African Journal of Biomedical Research, Vol. 9 (2006); 149 - 156

ISSN 1119 - 5096 (c) Ibadan Biomedical Communications Group

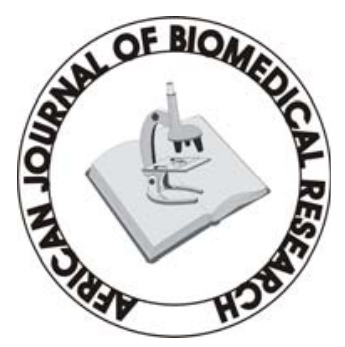

Full-text available at http://www.ajbrui.com http://www.bioline.br/md http://www.ajol.com

Received:

July 2006

Accepted (Revised):

September 2006

Published

September, 2006
Full Length Research Article

\section{Prevalence and Pattern of Back Pain among Pregnant Women Attending Ante-Natal Clinics in Selected Health Care Facilities}

\author{
*Ayanniyi O, *Sanya A.O, **Ogunlade S.O, ${ }^{+}$Oni-Orisan M.O
}

Departments of *Physiotherapy and **Surgery

College of Medicine, University of Ibadan, Nigeria.

${ }^{+}$Department of Community Medicine

College of Health Sciences, Lautech,

Osogbo Campus, Osogbo, Nigeria

\section{ABSTRACT}

Back pain is (BP) is recognized as an important problem in pregnancy. The objectives of this study were to examine the prevalence and pattern of back pain (BP) in pregnancy. A survey of 2,187 pregnant women attending ante-natal clinics in selected Medical facilities in Ibadan and Ogbomoso, Nigeria was carried out using pre-tested close-ended questionnaire. Information on prevalence, pattern and characteristics of back pain in pregnancy were obtained. Data obtained was analyzed using both descriptive and inferential statistics of mean, standard deviation, and inferential statistics of independent t-tests and chi-square tests. One thousand and eight (52.5\%) of the 1919 included subjects had back pain in pregnancy. The mean age of those with and without back pain was $26.8 \pm 5.3$ and $27.1 \pm 5.4$ years respectively. Mean number of pregnancy was higher in subjects with back pain than those without back pain. The pain site among the 1008 subjects with back pain was low back in 669 subjects (66.4\%), posterior pelvic in 242 subjects (24.0\%) and high back in 97 subjects (9.6\%). Among the subjects with back pain, 315 (31.3\%) and 53 (5.3\%) were in their first and sixth pregnancies respectively. Postural modification relieved the back pain in about 50\% of the subjects across the three back pain groups during pregnancy. It was concluded that back pain is a common and real complaint in pregnancy. It is therefore recommended that rather than dismiss it as trivial, back pain in pregnancy should be attended to as part of ante-natal care.

(Afr. J. Biomed. Res. 9: 149 - 156)

Keywords: Back pain; Pattern; Pregnancy

*Address for Correspondence (e-mail Address): mckdalos@yahoo.com

Abstracted by:

African Index Medicus (WHO), CAB Abstracts, Index Copernicus, Global Health Abstracts, Asian Science Index, Index Veterinarius, Bioline International , African Journals online 


\section{INTRODUCTION}

Back pain (BP) is a major complaint encountered in clinical practice world-world (White and Gordon, 1982; Cypress, 1983). Back pain is not a diagnosis, but it is a symptom that occurs in a wide variety of medical, musculo-skeletal, and neurological conditions (Roach et al, 1997). According to Hipp et al (1989) back pain is considered to be a symptom of a variety of changes and disorders affecting the lumbar spine, the sacro-coccyx and pelvis, but it may also be a symptom of disorders affecting the neighbouring organs. In extent, back pain affect the area between first thoracic vertebrae and gluteal folds and often radiates into the anterior chest wall and the thighs Love and Schorn, 1965; McKenzie, 1990). The problem of back pain in pregnancy has attracted attention of clinicians and researchers from all over the world ( Golighty, 1982; Nwuga, 1982; Fast et al; 1987; Ostgaard et al; 1994; Davidson and Hansen, 2000; Sanya and Olajitan 2001). According to May, (2000) there is no doubt that back pain is one of the most common problems associated with pregnancy and consequently it has been accepted as almost inevitable (Fung et al; 1993; MacEvilly and Buggy, 1994).

Retrospective studies indicates a prevalence of 48 to 56\% (Mantle et al; 1977; Fast et al; 1987) while a prospective study, which followed pregnant women from the twelfth week found the overall nine-month period prevalence to be 4\% (Ostgaard et al; 1991). Mens et al (1996) implicated pregnancy as an important risk factor for development of chronic back pain. According to De Joseph and Cragin (1998) many women experience their first episode of back pain during pregnancy while at least half of all pregnant women experienced back pain at some time during pregnancy while some of them also have persisting back pain post-partum (Nilsson-Wikmar et al; 1999).

A number of authors (Ostgaard et al; 1991; Kristiansson et al; 1996; Noren et al; 1997) have identified two major sub-types of back pain (lumbar and posterior pelvic pain) affecting the lower portion of the spine in pregnancy. Similarly, Ostgaard et al; (1991 ) and Noren et al; (1997) further described three back pain groups in pregnancy depending on the site of the pain. The three back pain groups are: high back pain (HBP) in the thoracic region; low back pain (LBP) in the lumbar region, and sacroiliac pain (SIP) in the region of the buttock and sacroiliac joint. These back pain groups are distinguished by the pain distribution and location; they are not determined by aetiological considerations (Ostgaard et al, 1991). However following the suggestion of Ostgaard and colleagues (1991) the term sacroiliac joint pain (SIP) was replaced by the term posterior pelvic pain (PPP) in order to take care of the uncertain or multifactoral aetiology of the sacroiliac joint pain in pregnancy. However, according to Perkins and colleagues (1998), notwithstanding the change in terminology many features of the posterior pelvic pain (PPP) syndrome are suggestive of sacroiliac joint problems.

Previous studies (Mantle et al, 1977; Fast et al, 1987; Ostgaard et al; 1991; Sanya and Olajitan, 2001) have made significant contributions towards recognizing the widespread problems of LBP during pregnancy, however, only few studies (Ostgaard et al; 1991 and Noren et al, 1997) have sought to explicitly describe the prevalence and pattern of BP among pregnant women in general. This present study was therefore designed to assess the prevalence and pattern of various back pain sub groups among pregnant women attending ante-natal clinics at some selected health facilities in Ibadan and Ogbomoso in Oyo state, Nigeria.

\section{MATERIALS AND METHODS}

Participants: A total of 2,187 pregnant women who were registered in six selected private and Government owned medical facilities with ante-natal clinics participated in the study. Excluded from the study were subjects who were unable to understand English or Yoruba language.

Material: The main instrument for this study was a researcher-administered close-ended questionnaire, which was designed to obtain information on subjects' demographic status, history of pregnancy, site of BP, behavior and severity of BP during pregnancy. The questionnaire used for this study was a modified version of the questionnaire designed by Sanya and Olajitan (2001), to assess the 
incidence of low back pain in pregnancy among post-natal subjects.

The questionnaire was modified for ante-natal subjects and expanded to accommodate other variables and subgroups of back pain. The questionnaire was assessed by experts in physiotherapy and Orthopaedic to ensure its face and content validity. A pilot study gave its testretest reliability to be $\mathrm{r}=.87$

Procedure: Ethical approval was obtained from each of the medical facilities where the study was conducted namely: Baptist medical centre, Ogbomoso; Livingspring medical Clinics, Ogbomoso; Ibrahim Taiwo Maternity Clinic, Ogbomoso; Oke-Ayo Maternity Clinic, Ogbomoso; State Hospital, Ogbomoso; and Adeoyo Maternity Hospital, Ibadan. The informed consent of the various heads of departments of the ante-natal Clinics and that of the participants were sought and obtained.

Consecutive sampling method (Adewuyi, 1996) was used to recruit participants into this study. The questionnaire survey was carried out by trained interviewers made up of final year physiotherapy students, third year medical students and community Health Attendants who were readily available at the time of the study. The recruited interviewers attended two training sessions lasting about fortyfive minutes each on how to administer the questionnaire.

Treatment of data: Data generated from each of the medical facilities were pooled together for analysis.

Statistical analysis : The following data analyses were carried out. Descriptive statistics of range, mean and standard deviation were computed for age and number of pregnancies.

(1) Chi-square tests were carried out to determine if statistical differences were present in subjects' population distribution among different back pain sub-groups and the no back pain group. Chi-square tests were also utilized to determine if there were statistical differences in the incidence of back pain across the gestational period (the three trimesters) among the three back pain sub-groups.
(2) Independent t-test was calculated to compare age and number of pregnancies, among subjects belonging to different sub-groups.

\section{RESULTS}

A total of 1919 (87.75\%) participants out of 2,187 pregnant women who were registered at the six selected medical facilities for ante-natal care satisfied the inclusion criteria for the study. One thousand and eight (52.5\%) participants had back pain (BP) and 911 (47.5\%) participants had no back pain (NBP).

The result showed that there were more pregnant subjects with low back pain (LBP) i.e. of the lumbar spine origin (34.9\%) than those with high back pain (HBP) i.e. of thoracic spine origin (5\%) and posterior pelvic pain (PPP) (12.6\%) put together as shown in Figure 1. Chi-square analysis indicated that there was significant difference $\left(\mathrm{X}^{2}=885.492\right.$; $\mathrm{P}=0.000$ ) in the proportion of the subjects belonging to the different groups i.e. NBP, LBP, HBP, and PP respectively. Distribution of subjects using class interval of age is as shown in Table 1. The highest population of subjects 730 (38.04\%) fell within age range of 25years to 29 years while the least population of subjects $2(0.10 \%)$ and $5(0.26 \%)$ fell between age range of 10 years to 14 years and 45 years to 49 years respectively.

Table 2 shows the pattern of distribution of the mean age of the subjects in the four groups (NBP, LBP, HBP and PPP). Subjects with HBP (26.18years) had the lowest mean age while the subjects with PPP (27.53years) had the highest mean age among the subjects in the four groups. One way analysis of variance for the mean age of the subjects across the the four groups was not significant $(\mathrm{F}=$ 1.095; $\mathrm{P}=0.328$.

The pattern of the distribution of the mean number of pregnancy among the subjects in the 4 groups is as shown in Table 3. Subjects in the PPP groups had the highest mean number of pregnancy (2.76 pregnancies) while the subjects with HBP had the lowest mean number of pregnancy (2.26 pregnancies). One way analysis of variance of the mean numbers of pregnancy across the four groups of subjects shows that there was a significant difference $(\mathrm{F}=5.064 ; \mathrm{P}=0.002)$. 
Table 1: Distribution of subjects using class interval of age

\begin{tabular}{ccccccc}
\hline Age- Range & NBP & LBP & PPP & HBP & Total & \% \\
\hline $10-14$ & 1 & 1 & - & - & 2 & $10 \%$ \\
$15-19$ & 47 & 30 & 13 & 5 & 95 & $5.0 \&$ \\
$20-24$ & 248 & 172 & 48 & 35 & 503 & $26.21 \%$ \\
$25-29$ & 350 & 261 & 88 & 31 & 730 & $38.00 \%$ \\
$30-34$ & 176 & 125 & 55 & 19 & 375 & $19.54 \%$ \\
$35-39$ & 64 & 63 & 30 & 2 & 159 & $8.29 \%$ \\
$40-44$ & 22 & 16 & 7 & 5 & 50 & $2.60 \%$ \\
$45-49$ & 3 & 1 & 1 & - & 5 & $.26 \%$ \\
Total & $\mathbf{9 1 1}$ & $\mathbf{6 6 9}$ & $\mathbf{2 4 2}$ & $\mathbf{9 7}$ & $\mathbf{1 9 1 9}$ & $\mathbf{1 0 0 \%}$ \\
\hline
\end{tabular}

Key: LBP = Low Back Pain (Lumbar); PPP = Posterior Pelvic Pain (Sacroiliac); HBP = High Back Pain (Thoracic); NBP = No Back Pain

TABLE 2: Pattern of Distribution of Mean Age of the subjects for the Four Groups ( $\mathrm{N}=1919)$

\begin{tabular}{|c|c|c|c|c|}
\hline Groups & No. of Subject & \% of Total Subjects & Age-Range (Years) & Mean Age \pm SD \\
\hline NBP & 911 & 47.5 & $14-45$ & $26.77 \pm 5.32$ \\
\hline LBP & 669 & 34.9 & $12-43$ & $27.08 \pm 5.30$ \\
\hline PPP & 242 & 12.6 & $16-45$ & $27.53 \pm 5.72$ \\
\hline HBP & 97 & 5.0 & $15-40$ & $26.18 \pm 5.24$ \\
\hline Total & 1919 & 100 & $12-45$ & $26.95 \pm 5.37$ \\
\hline
\end{tabular}

TABLE 3: Pattern of Distribution of Mean Number of Pregnancy of the Subjects for the four Groups ( $=1919)$

\begin{tabular}{|c|c|c|c|c|}
\hline Groups & No. of Subject & \% of Total Subjects & Pregnancy Range & Mean Pregnancy \pm SD \\
\hline NBP & 911 & 47.5 & $1-6$ & $2.44 \pm 1.44$ \\
\hline LBP & 669 & 34.9 & $1-6$ & $2.64 \pm 1.49$ \\
\hline PPP & 242 & 12.6 & $1-6$ & $2.76 \pm 1.65$ \\
\hline HBP & 97 & 5.0 & $1-6$ & $2.26 \pm 1.39$ \\
\hline Total & 1919 & 100 & $1-6$ & $2.54 \pm 1.49$ \\
\hline
\end{tabular}

TABLE 4: Distribution of subjects using the Number of Pregnancy

\begin{tabular}{ccccccc}
\hline No. of Pregnancy & NBP & LBP & PPP & HBP & No. of Subjects & \% of Total Subjects \\
\hline 1 & 321 & 198 & 79 & 38 & 636 & 33.14 \\
2. & 214 & 160 & 46 & 26 & 446 & 23.24 \\
3. & 152 & 125 & 37 & 14 & 328 & 17.09 \\
4. & 128 & 92 & 31 & 10 & 261 & 13.60 \\
5. & 66 & 62 & 33 & 4 & 165 & 8.60 \\
6. & 30 & 32 & 16 & 5 & 83 & 4.33 \\
Total & 911 & 669 & 242 & 97 & 1919 & 100 \\
\hline Key: NBP = No Back Pain; LBP & L Low Back Pain; PPP & $=$ & Posterior Pelvic Pain; HBP & - High Back Pain;
\end{tabular}

Key: NBP = No Back Pain; LBP = Low Back Pain; PPP = Posterior Pelvic Pain; HBP = High Back Pain;

Table 4 shows the distribution of the subjects' population using the number of pregnancy (gravidity). Subjects with first pregnancy were in the majority 636 (33.14\%) while subjects with sixth pregnancy were in the minority 83 (4.33\%). The population of the subjects thus reduced with 
increased gravidity.

Table 5:

Pattern of Distribution of the three Back Pain Types among subjects with Back Pain ( $\mathrm{N}=1008)$

\begin{tabular}{lcc}
\hline Back Pain Type & $\mathrm{n}$ & $\begin{array}{c}\text { \% of } \\
\text { Total }\end{array}$ \\
\hline LBP as Principal Complaint & 669 & 66.4 \\
PPP as Principal Complaint & 242 & 24.0 \\
HBP as Principal Complaint & 97 & 9.6 \\
LBP Only & 608 & 60.3 \\
PPP Only & 223 & 22.1 \\
HBP Only & 85 & 8.4 \\
LBP + PPP combination & 41 & 4.1 \\
LBP + HBP combination & 31 & 3.1 \\
PPP + HBP combination & 15 & 1.5 \\
LBP + PPP + HBP combination & 05 & 0.5
\end{tabular}

Key: NBP = No Back Pain; $L B P=$ Low Back Pain; PPP =

Posterior Pelvic Pain; HBP = High Back Pain;
The pattern of the distribution of the three back pain types (LBP, HBP and PPP) among the studied population is as shown in Table 5. LBP, HBP and PPP were predominant complaint in $66.4 \%$, $24.0 \%$ and $9.6 \%$ of the subjects respectively. The study also revealed that various combination presentations of the three BP types were also common among the individual subjects. Chi-square analysis indicated that there was significant difference $\left(\mathrm{X}^{2}=562.327\right.$; $\mathrm{P}=0.00)$ in the proportion of the subjects with principal complaint of LBP, HBP and PPP respectively.

The pain profile of the subjects across the three back pain types as collated through subjective self rating of $\mathrm{BP}$ severity during current pregnancy revealed that subjects with moderate pain were in the majority (LBP: 48.1\%, PPP: 48.8\%, HBP: 40.2\%) followed by subjects with mild BP while subjects with severe BP were in the minority (LBP: 20.1\%; PPP: 23.6\%; HBP: 23.7\%).

TABLE 6: Self Report of Period of the Day when Back Pain disturbed the subject most

\begin{tabular}{llll}
\hline & LBP $(\mathrm{N}=669)$ & PPP $(\mathrm{N}=242)$ & HBP $(\mathrm{N}=97)$ \\
\hline & & & \\
Morning & $106(15.8 \%)$ & $47(19.4 \%)$ & $19(19.6 \%)$ \\
Afternoon & $100(14.9 \%)$ & $80(33.1 \%)$ & $27(27.8 \%)$ \\
Evening & $116(17.3 \%)$ & $18(7.4 \%)$ & $23(23.7 \%)$ \\
Night & $157(23.5 \%)$ & $27(11.2 \%)$ & $27(27.8 \%)$ \\
Not Sure OR Varying & $190(28.4 \%)$ & $70(28.9 \%)$ & $1(1.1 \%)$ \\
\hline
\end{tabular}

Table 7: Incidence of Back Pain across the three Trimesters of Pregnancy among the study Subjects

\begin{tabular}{lllllll}
\hline Sub-Group & 1st Trimester & 2nd Trimester & 3rd Trimester & $\mathrm{X}^{2}$ & & P \\
\hline & & & & & & \\
HBP $(\mathrm{n}=97)$ & $25(25.8 \%)$ & $46(47.4 \%)$ & $34(35.1 \%)$ & 6.343 & 0.042 & Significant \\
LBP $(\mathrm{n}=669)$ & $168(25.3 \%)$ & $215(32.1 \%)$ & $290(43.3 \%)$ & 33.208 & 0.000 & Significant \\
PPP $(\mathrm{n}=242)$ & $82(33.9 \%)$ & $73(30.2 \%)$ & $119(49.2 \%)$ & 13.015 & 0.001 & Significant \\
Total & 276 & 334 & 443 & & & \\
\hline
\end{tabular}

With respect to the subjects' perception of the behavior of their BP types from time to time during the current pregnancy. Subjects with complaint of intermittent BP were consistently in the majority (LBP: 74.3\%; PPP: 71.9\%; HBP: 73.1\%) while subjects with continuous BP were also consistently in the minority (LBP: 25.1\%; PPP: 28.1\%; HBP: 26.8\%). The nature of the subjects BP was reported as either sharp or dull pain. Subjects with sharp BP were in the minority across the three BP types. LBP $=33.2 \%$; $\mathrm{PPP}=39.7 \%$; $\mathrm{HBP}=37.0 \%$; while subjects with dull BP were in the majority across the three BP groups: $\mathrm{LBP}=66.2 \%$; $\mathrm{PPP}=60.3 \%$; AND $\mathrm{HBP}=63 \%$.

With respect to the self report of effects of postural changes on the subjects BP, 297 (44.4\%) of 
the subjects with LBP reported that their BP was affected by postural changes, while 162 (66.9\%) of the subjects with PPP and 54 (55.7\%) of the subjects with HBP stated that their BP was equally affected by postural changes. On the other hand 372 (55.6\%) of the subjects with LBP and 80 (33.1\%) of the subjects with PPP and 43 (44.3\%) of the subjects with HBP stated that their BP was not affected by postural changes. With regard to the direction and pattern of pain changes due to postural modifications: 23 (7.7\%) of the subjects with LBP had their BP increased while 39 (24.1\%) and twelve (22.2\%) of the subjects with PPP and HBP also had their BP increased as a result of postural changes. Decreased in BP and a result of postural changes across the three BP groups were as follows: LBP = 274 (92.3\%); PPP = 123 (75.9\%) and HBP = 42 (77.8\%) respectively. These results indicated that high proportion of the subjects across the three BP groups had their BP ameliorated by postural changes; this effect is more pronounced in the subjects with LBP.

Information on the subjects self reported period of the day when their back pain (BP) complaints disturbed them the most is as shown in Table 6 substantial number of subjects in the LBP and PPP groups respectively could not pin point a single period of the day when they were most disturbed by their BP problem. With respect to the pattern of incidence/occurrence of back pain across the three trimesters of pregnancy among the subjects in the three BP groups of LBP, HBP and PPP is as shown in Table 7. The incidence of BP was at its highest peak in the third trimester of pregnancy for subjects with LBP and PPP whereas subjects suffering from HBP recorded their highest peak of incidence of BP at second trimester of pregnancy. However, the combined groups' data presented a picture of gradual increases in the incidence of BP across the three trimesters from the first trimester (27.4\%) to the third trimesters with highest peak (43.9\%) (Table 7).

\section{DISCUSSION}

The population of the subjects with no Back Pain (NBP) and those with back pain (BP) were nearly evenly distributed among the studied population but with subjects having BP in slight majority (52.5\%). This finding is supported by previous studies (MacEvilly and Buggy, 1996; and Perkins et al., 1998) which highlighted that BP is a common complaint of women during pregnancy. It has also been noted that at least $50 \%$ of pregnant women will experienced BP to some extent during pregnancy (Fast et al., 1987; Ostgaard et al., 1994; Sydsjo et al., 1998; Sanya and Olajitan 2001). However, there was significant difference in the proportion of the subjects belonging to the four different groups i.e. no back pain (NBP), Low back pain (LBP); High back pain (HBP) and Posterior pelvic pain (PPP). With respect to the three $\mathrm{BP}$ sub-groups, subjects with LBP were in the majority $(66.37 \%)$ and were more than subjects with PPP (24.01\%) and HBP (9.62\%) put together. This finding with respect to proportional distribution across the three BP subgroups is in complete disagreement with that of Colliton (1996) who stated that PPP is approximately four times as prevalent as LBP during pregnancy. The finding from this study is equally at variance with the findings of Ostgaard et al., (1991) and Noren et al., (1997) which gave a distribution pattern of PPP 50\%, LBP $40 \%$ and HBP $10 \%$. The finding of Ostgaard et al. (1991) and Noren et al., (1997) thus gave an impression that subjects with PPP constituted half or more of women with BP during pregnancy. However, the finding from this present study is consistent with that of Albert et al., (2002) who reported an incidence rate of $20.1 \%$ for PPP among pregnant women with BP in their study. The finding in this study with respect to the distribution of HBP among the surveyed population of pregnant women is consistent with findings of Ostgaard et al., (1991) and Noren et al., (1997). The finding with respect to the distribution of LBP among the pregnant women in this present study is at variance with the findings of Ostgaard et al., (1991) and Noren et al (1997) who found the proportion of LBP incidence to be lower than that of PPP incidence in their study. However, taking as a whole the finding of this study is consistent with previous studies (Mantle et al., 1997; Fast et al., 1987, Orvieto et al., 1994) that stated that at least $50 \%$ of pregnant women will suffer from back pain during pregnancy. In these studies no clear distinction was made of PPP problem as a separate 
BP entity.

\section{REFERENCES}

Adewuyi, J.F. (1996). Biostatistics: A Foundation course in Health Sciences. 1st Edition, Ibadan, Nigeria. Yotson Consult Communications 163 - 174. Albert, H.B., Godskesen, Westergaard (2002). Incidence of four syndromes of pregnancy-related pelvic joint pain. Spine: 27 (24) 2831 - 2834.

Anderson G.B.J. (1999). Epidemiologic Feature of chronic low-back pain Lancet 354: 581 - 585.

Boissonnault W, DiFabio RP (1996) Pain profile of patients with low back pain referred to physical therapy. Journal of Orthopaedic Physical Therapy 24. 180 - 191.

Bookhout, M.M., and Boissonault, W.G., (1988). Physical therapy mangement of Musculoskeletal Disorders during Pregnancy. In: E. Wilder (Ed.). Obstetric and Gynaecology Physical Therapy, Churchill-Livingstone, New York, Pp. 17 - 62.

Brynhildsen J.O.; Bjors E., Skarspgard C., Hammar M.L. (1998). Is hormone replacement therapy a risk factor for low back pain among postmonopausal women? Spine. 23(7): 809 - 13.

Cailliet R. (1981). Low back pain Syndrome. 3rd Edition, Philadelphia F.A. Davis Company Pg. 50 57.

Colliton J. (1996). Back pain and Pregnancy: Active management strategies. The Physician and Sports Medicine. 24(7): 89 - 93.

Cypress, B. K. (1983). Characteristics of Physician visits for back symptoms: A National perspective. American Journal of Public Health. 73: 389 - 395. Cyriax, J. (1978). Textbook of Orthopaedic Medicine. Volume 1: Diagnosis of Soft Tssue Lesions. 7th Edition. London, England, Bailliera Tendal 348 - 573.

Davidson M., Hansen, T.M. (2000). Pregnancy associated pelvic pain II: Symptoms and Clinical findings. Ugeskrift fur Leager. 162(36): 4813-7.

De Joseph J.F., Cragin, L. (1998). Biomedical and Feminist perspectives on low back pain in pregnancy. Nursing clinics of North America 33(4): 713 - 4.

Fast, A. Shapiro D. Ducommun E.J. (1987). Low back pain in pregnancy. Spine 12 - 368 - 371.
Frymoyer, J.W.; Poper, M.H. Costanza, M.C., Rosen J.C., (1980). Epidemiologic Studies of low back pain. Spine 5(5): 419 - 23.

Fung, B.K. Kwong, C.M., Ho, E.S. (1993). Low back pain of Women during pregnancy in the mountainous district Central Taiwan. Chung Hau/Asuch Tsa Chih-Chinese Medical Journal. 51(2) 103 - 106.

Golighty, R. (1982). Pelvic Arthropathy in Pregnancy and the peurperium. Physiotherapy. 68(7): 216 - 220.

Hipp, R.; Gradinger R.; Flock K.; Opitz, G; Hipp E. (1989). Backache causes, Diagnosis and therapy. Fortschritteder Medizin. 107(18) 36: 39 - 44.

Kristiansson P. Svardsudd, K.; Von Schooltz B. (1996). Back pain during pregnancy. A prospective study. Spine. 21: 702 - 709.

Love, JG; Schorn (1965). Thoracic-Disk Protrusions. Journal of American Medical Association 191: (18): $627-630$.

MacEvilly M; Buggy D (1996). Back pain and pregnancy: A review Pain 64, 405 - 411.

Mantle, M.J.; Greewood R.M.; Currey H.L.F. (1977). Backache in pregnancy. Rheumatism and Rehabilitation. 16: 95 - 101.

May S. (2000). Back Pain and Pregnancy - A Review McKenzie (U.K.) Newsletter 8: 3-14.

McGuire J. L. (1989). Arthropathies Associated with Endocrine Disorder in Kelley, Harris, Ruddy and Sledge C. (Eds.) Text-book of Rheumatology 3rd Edition Philadelphia. London, Toronto, Montre. Sydney, Tokyo. W.B. Saunders Co. Harcourt Brace Jonanovich, Inc. Chapter 94, 1648 - 1665.

McKenzie, R. A. (1981). The Lumbar Spine: Mechanical Diagnosis and Therapy. 1st Edition Waikanae, New Zeland. Spinal Publication 81 - 120.

McKenzie, R. A. (1990). The Cervical and Thoracic Spine: Mechanical Diagnosis and Therapy. 1st Edition Weikanae. New Zeland Spinal Publication XIX - 56.

McKenzie, R.A. (1980). Treat Your Own Back Waikanae,. New Zealand. Spinal Publication 67 69.

Melzack R.; Belanger E. (1989). Labour Pain: Correlation with Menstrual pain before and during pregnancy. Pain 36(2): 225 -9.

Mens J.M.A.; Vleeming, A.; Stoeckart, R.; Stan H.J.; Snijders C.J. (1996). Understanding 
Peripartum Pain. Implication of a patient Survey. Spine 21: 1363 - 1370.

Nilsson-Wikmar (1996), L.; Harms-Ringdahl, K.; Pilo, C. Palhiback M. (1999). Back Pain in Women Postpartum is not a unitary Concept. Physiotherapy Research International 4(3): 201 - 13.

Noren L.; Ostgaard, S.; Nielsen, T.F.; Ostgaard, N.C. (1997). Reduction of Sickleave for Lumber back and posterior pelvic pain in pregnancy. Spine 22: 2157 - 2160.

Nwuga, V.C.B. (1982). Pregnancy and Back Pain Among Upper Class Nigerian Women. The Australian Journal of Physiotherapy 28(4): 8 - 1.

Orvieto R.; Achiron A.; Ben-Rafael Z.;Gelernter I.; Achiron R. (1994). Low Back Pain of Pregnancy. Acta Obstetricia et Gynecologica Scandinavica 73(3): 209 - 14.

Ostgaard, H. C.; Anderson G. B.; Wennergren, M. (1991). The impact of low back and pelvic pain in Pregnancy on the pregnancy outcome. Acta Obstetricia et Gynecologica Scandinavica. 70(1): 21 $-4$.

Ostgaard. H.C.; Zetherstrom G. Roost Hansson E.; Svanberg B. (1994). Reduction of Back and Posterior Pelvic Pain in Pregnancy. Spine 19894 900.

Ostgaard, H.C. (1996). Assessment and Treatment of Low Back Pain in Working Pregnant Women. Seminar in perinatology 21: 61 - 69.

Ostgaard, H.C.; Roos-Hansson E.; Zetherstrom G. (1996). Regression of back and posterior pelvic pain after pregnancy. Spine 21(23): 2777 - 80.

Ostgaard, H.C. (1997). Lumbar Back and Posterior Pelvic Pain in Pregnancy. In: Movement, Stability and Low Back Pain. The Essential Role of the Pelvis. (Eds.) Vleeming A.; Mooney V.; Dorman T.; Snijders C., Stoeckart, R.; Churchill Livingstone, New York 52 - 61.

Ostgaard, H.C.; Zetherstrom, G.; Roos-Hansson E. (1997). Back Pain in Relation to Pregnancy. A 6year follow-up. Spine. 22: 2945 - 2950.

Perkins J.; Hammer R. L.; Loubert P. V. (1998). Identification and mangement of pregnancy-related low back pain. Journal of Nurse-Midwifery: 43(5):
$331-40$.

Picavert, H.S.J (2002) Catestrophizing, Kinesiophobia and Low Back Pain in the general population, presented at International Forum for Primary Care Research on Low Back Pain, Montreal (Abstract). Back Letter 17 (8): 88.

Pincus T. (2002). A systematic review of psychological factors as predictors of chronicity/disability in prospectively cohorts of Low Back Pain. Spine (Electronic version) 27E 109-120. Porter, R. W. (1993). Management of back pain. 2nd Edition. Londong. New York Churchill Livingstone. 19 - 342.

Roach, K. E. Brown, M. D.; Albin, R.d. (1997). The Sensitivity and Specificityof Pain response to activity and position in categorizing patients with low back pain. Physical Therapy. 77(7): 730 - 738. Sanya, A. O. and Olajitan A. (2001). Incidence of Low Back Pain in Pregnancy. African Journal of Biomedical Research. 4: 57 - 60.

Stgaard, H.C.;Andersson, G.B.J.; Karlsson K. (1991b). Prevalence of Back Pain during Pregnancy. Spine 16: 549 - 552.

Sydsjo, A.; Sydsjo G.; Wihma B. (1998). Increase in sick leave rate caused by back pain among pregnant Swedish Women after Amelioration of social benefits. A paradox Spine 23(18): 1986 -90.

Turgut, F. Turgut M., Cetinsahim, M. (1998). A prospective study of persistent back pain after pregancy. European Journal of Obstetrics, Gynecology and Reproductive Biology. 80(1): 45 48.

Vlaeyen, J.W.S. (2002). The treatment of fear of movement/reinjury in Chronic low back pain: Further evidence on the effectiveness of exposure in vivo, Clinical Journal of Pain 18 (4): 251 - 62

White A. A.; Gordon, S. L. (1982). Synopsis. Workshop on idiopathic low back pain. Spine. 7: 141 - 149 